\title{
Controlled-Type ZVS Technique without Auxiliary Components for Micro-inverters
}

\author{
Qian Zhang ${ }^{\dagger}$, Dehua Zhang ${ }^{*}$, Haibing $\mathrm{Hu}^{* *}$, John Shen $^{* * *}$, and Issa Batarseh ${ }^{* * * *}$ \\ $\dagger^{* * * *}$ Dept. of Electronic Eng., University of Central Florida, Orlando, USA \\ "Dept. of Electronic Eng., Zhejiang University, Zhejiang, China \\ ${ }^{* *}$ Dept. of Electronic Eng., Nanjing University of Aeronautics and Astronautics, Nanjing, China \\ ${ }^{* *}$ Dept. of Electrical and Computer Eng., Illinois Institute of Technology, Chicago, USA
}

\begin{abstract}
This paper proposes a Boundary Current Mode (BCM) control scheme to realize soft switching on a conventional single phase full bridge DC/AC inverter. This technique with the advantages of no auxiliary components, low cost, high efficiency, and simple in control, is attractive for micro-inverter applications. The operation principle and characteristic waveforms of the proposed soft switching technique are analyzed in theory. A digital controller is provided based on that theory. To balance the requirements of efficiency, switching frequency, and inductor size, the design considerations are discussed in detail to guide in BCM inverter construction. A $150 \mathrm{~W}$ prototype is built under these guidelines to implement the BCM control scheme. Simulation and experiment results demonstrate the feasibilities of the proposed soft switching technique.
\end{abstract}

Key words: BCM, Inverters, Soft-switching techniques

\section{INTRODUCTION}

Micro-inverters have received a great deal of attention from industry and in academic fields due to its advantages of easy installation, simple maintenance, maximum energy harvest and safe operation. However, cost, power density, efficiency and reliability still present major barriers to the implementation of micro-inverters on a large scale [1]. A higher switching frequency is an effective way to increase the power density and reduce the cost. However, a higher switching frequency induces higher power losses and more EMI. To solve these problems and maintain a high frequency, soft switching is one of the best options. A variety of soft switching techniques have been proposed for inverter applications [2]-[14]. They can be classified into three groups: load resonant [2], [3], resonant link [4]-[9], and resonant transition [10]-[14]. However, most of these require special

Manuscript received Feb. 16, 2013; revised Jul. 29, 2013

Recommended for publication by Associate Editor Bor-Ren Lin.

${ }^{\dagger}$ Corresponding Author: louisa1216@gmail.com

Tel: +1-321-609-1653, University of Central Florida

*Dept. of Electronic Eng., Zhejiang University, China

${ }^{* *}$ Dept. of Electronic Eng., Nanjing University of Aeronautics and Astronautics, China

${ }^{* * *}$ Dept. of Electrical and Computer Eng., Illinois Institute of Technology, USA

Dept. of Electronic Eng., University of Central Florida, USA inverter topologies, auxiliary resonant components, additional switches, and complex control algorithms, resulting in size and cost increases in inverter systems.

To reduce the number of resonant components, several soft switching techniques have been proposed in the last decade [15]-[19]. Some of these techniques employ a partial inverter circuit to form the resonant network [15]-[18]. For example, literature [15], [16] employ a leakage inductor of the flyback transformer to achieve ZVS on the main switch. Literature [17] employs a parasitic capacitor of the main switches and leakage inductor of the transformer to form the resonant network. Literature [18] proposed a ZVS control for a buck PFC converter, which employed the intrinsic capacitors of semiconductors and a buck inductor to form a resonant circuit. Literature [19] is based on DCM operation to realize ZCS control. No resonant components are required in [19]. The realization of the ZCS depends entirely on the current-zero-detection circuit.

In this paper, a soft switching technique is proposed based on the conventional full-bridge DC/AC inverter topology. The parasitic capacitors of the MOSFETs and the filter inductor in the inverter are employed to form a resonant network. By adopting a digital controller, the inductor current is constrained to operating under the Boundary Current Mode and zero voltage switching (ZVS) operation is realized. 


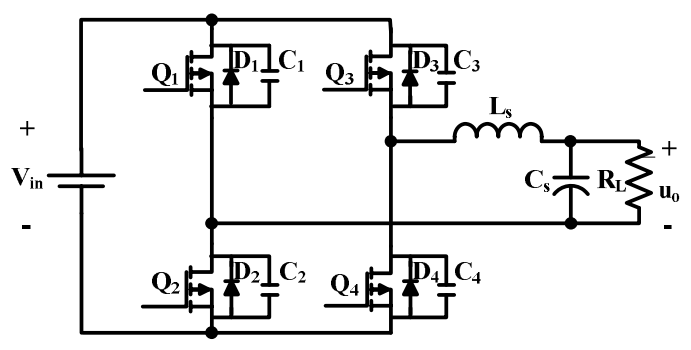

Fig. 1. Single-phase inverter topology.

Compared with the ZVS techniques in [15]-[17], which require additional resonant components and complex driver signals, the proposed $\mathrm{BCM}$ inverter requires no auxiliary components. Moreover, the control circuit is simple since only a pair of high frequency signals complementary to each other are required. Compared with the ZVS in [18], which has a non-operation period dependent on Vin/Vo, the BCM operation is controlled wholly with driver signals. Compared with the ZCS in [19], the BCM inverter does not require a current-zero-detection circuit, which is sensitive to noise.

This paper is laid out as follows. The operating principle and controller design of the BCM inverter are analyzed in section II. Section III discusses the design guideline for the BCM inverter with an example provided. In sections IV and $\mathrm{V}$ simulations are carries out and an experiment prototypes is built to implement the proposed control scheme and design guideline. Section VI concludes that the controlled-type ZVS technique and design guideline are feasible and effective.

\section{OPERATION PRINCIPLE AND CONTROL DESIGN}

\section{A. Operation Principle}

Fig.1. shows a full-bridge topology for a single-phase inverter with one leg (Q1 and Q2) operating at a high switching frequency and the other leg (Q3 and Q4) operating at the line frequency. The body diode and the parasitic output capacitor of the MOSFET are represented as the diode and capacitor anti-parallel connected with the switch in Fig. 1. To generate the ZVS condition during commutations, the inductor current is intentionally operated bi-directionally in every switching cycle, as shown in Fig. 2, which is referred to as the BCM in this paper.

To simplify the analysis, assume that the whole inverter system has achieved the steady state. Depending on the polarity of the output voltage, the operation of the inverter can be divided into two modes: $1 . V_{0}>0 ; 2 . V_{0}<0$. Each mode has six stages as shown in Fig. 3 and Fig. 4. The detailed analysis is as follows.

\section{Mode $1\left(\mathrm{~V}_{\mathrm{o}}>0\right)$}

Stage $1\left[\mathrm{t}_{0}-\mathrm{t}_{1}\right]$ : During this stage $\mathrm{Q}_{2}$ and $\mathrm{Q}_{3}$ are on, whereas $\mathrm{Q}_{1}$ and $\mathrm{Q}_{4}$ are off. The $\mathrm{DC}$ voltage transfers energy to the

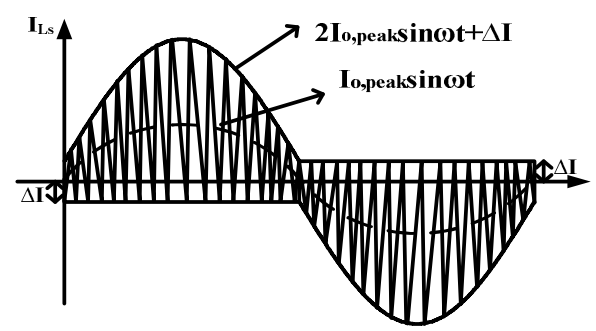

Fig.. 2. Inductor current waveform.

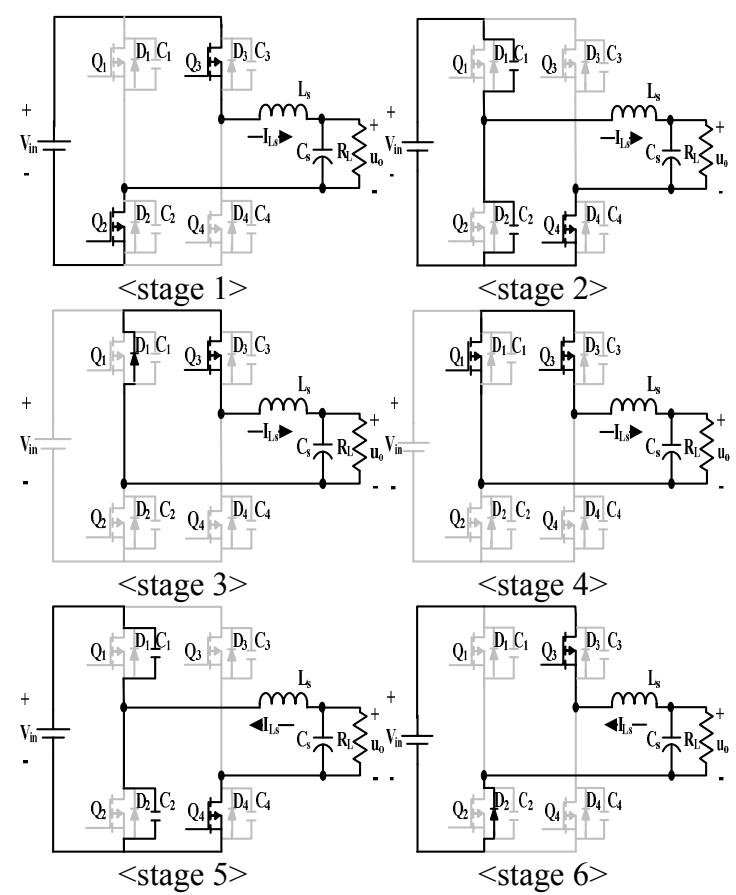

Fig. 3. Operation stages for the BCM inverter.

inductor and the inductor current increases linearly. The voltage across body capacitor $\mathrm{C}_{2}$ is zero, and the voltage across capacitor $\mathrm{C}_{1}$ is equal to the input voltage

$$
\left\{\begin{array}{c}
\mathrm{i}_{\mathrm{Ls}}(\mathrm{t})=\frac{\left(\mathrm{V}_{\text {in }}-\mathrm{u}_{\mathrm{o}}\right)}{\mathrm{Ls}_{\mathrm{s}}} \mathrm{t}+\mathrm{i}_{\mathrm{Ls}}\left(\mathrm{t}_{0}\right) \\
\mathrm{V}_{\mathrm{C}_{2}}(\mathrm{t})=0 \\
\mathrm{~V}_{\mathrm{C}_{1}}(\mathrm{t})=\mathrm{V}_{\text {in }}
\end{array}\right.
$$

Stage $2\left[t_{1}-t_{2}\right]$ : When the inductor current reaches the expected peak current at time $t_{1}, Q_{2}$ is turned off. The output capacitors of MOSFETs $\mathrm{C}_{1}$ and $\mathrm{C}_{2}$ are charged and discharged respectively through the inductor current until $\mathrm{C}_{1}$ is fully discharged. The status expressions are depicted as:

$$
\left\{\begin{array}{c}
V_{C_{2}}(t)=k_{1} \cos \left(\omega_{0} t\right)+k_{2} \sin \left(\omega_{0} t\right)+V_{d}-V_{o} \\
i_{L_{s}}(t)=\frac{1}{Z_{0}}\left(-k_{1} \sin \left(\omega_{0} t\right)+k_{2} \cos \left(\omega_{0} t\right)\right)
\end{array}\right.
$$

Where:

$\mathrm{k}_{1}=\frac{\mathrm{V}_{\mathrm{o}} \cos \left(\omega_{\mathrm{o}} \mathrm{t}_{1}\right)-\mathrm{I}_{\mathrm{p}}+\mathrm{Z}_{0} \sin \left(\omega_{\mathrm{o}} \mathrm{t}_{2}\right)}{\cos \omega_{0}\left(\mathrm{t}_{1}-\mathrm{t}_{2}\right)}$ 


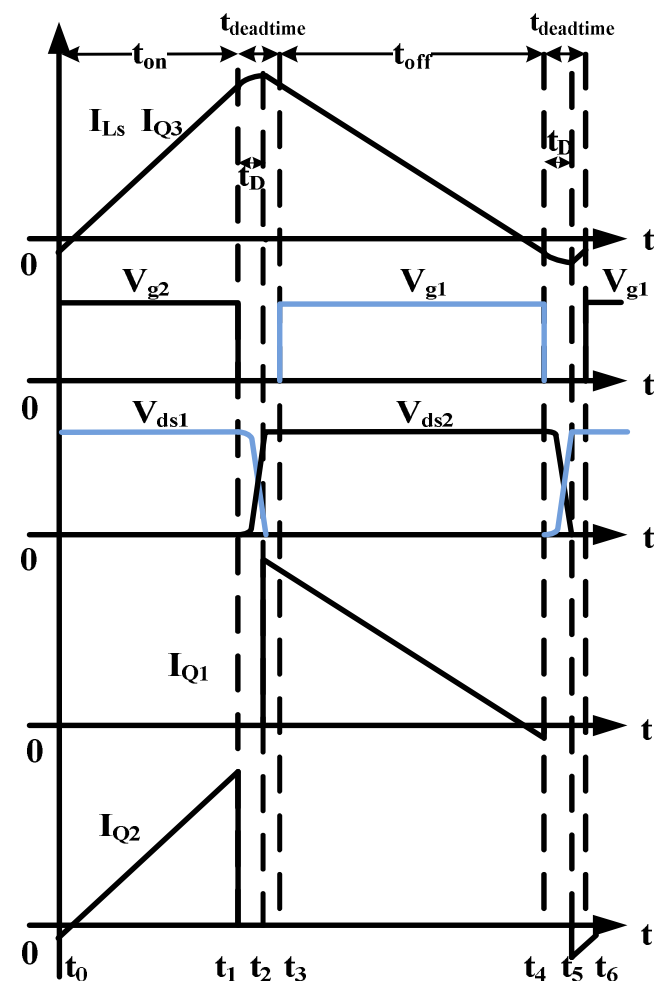

Fig. 4. Key waveforms in one switching cycle.

$\mathrm{k}_{2}=\frac{\mathrm{V}_{\mathrm{o}} \sin \left(\omega_{0} \mathrm{t}_{1}\right)+\mathrm{I}_{\mathrm{p}}+\mathrm{Z}_{0} \cos \left(\omega_{0} \mathrm{t}_{2}\right)}{\cos \omega_{0}\left(\mathrm{t}_{1}-\mathrm{t}_{2}\right)} \quad, \quad \omega_{0}=1 / \sqrt{2 \mathrm{CLs}}$, $\mathrm{Z}_{0}=\sqrt{\mathrm{Ls} / 2 \mathrm{C}}, \mathrm{C}_{1}=\mathrm{C}_{2}=\mathrm{C}$

Stage $3\left[t_{2}-t_{3}\right]$ : As $C_{2}$ is charged to the DC bus voltage, the inductor current freewheels through body diode $\mathrm{D}_{1}$, creating the zero voltage switching condition for $\mathrm{Q}_{1}$. The inductor current flows through body diode $\mathrm{D}_{1}$ and decreases linearly, as shown in $<$ stage $3>$ of Fig. 3 .

$$
\left\{\begin{array}{c}
\mathrm{i}_{\mathrm{Ls}}(\mathrm{t})=\frac{\left(-\mathrm{u}_{0}\right)}{\mathrm{L}_{\mathrm{s}}} \mathrm{t}+\mathrm{i}_{\mathrm{Ls}}\left(\mathrm{t}_{2}\right) \\
\mathrm{V}_{\mathrm{C}_{2}}(\mathrm{t})=\mathrm{V}_{\text {in }} \\
\mathrm{V}_{\mathrm{C}_{1}}(\mathrm{t})=0
\end{array}\right.
$$

Stage $4\left[\mathrm{t}_{3}-\mathrm{t}_{4}\right]$ : At time $\mathrm{t}_{3}$, with the arrival of the driver signal for $\mathrm{Q}_{1}$, the conductivity of the MOSFET increases. Thus, the inductor current can be regarded as shifting from the body diode $\mathrm{D}_{1}$ "channel" to the $\mathrm{Q}_{1}$ conductive "channel". With the output voltage across inductor $\mathrm{L}_{\mathrm{s}}$, the inductor current decreases linearly to zero and then increases in the negative direction. The status equations are the same as those in stage 3.

Stage $5\left[t_{4}-t_{5}\right]$ : At time $t_{4}, Q_{1}$ is turned off. The negative peak current charges capacitor $\mathrm{C}_{1}$ to the DC bus voltage and discharges capacitor $\mathrm{C}_{2}$ to the zero voltage, respectively. The status equations are the same as those in stage 2 .
Stage $6\left[\mathrm{t}_{5}-\mathrm{t}_{6}\right]$ : When the voltage across $\mathrm{C}_{1}$ reaches the DC bus voltage, and the voltage across $\mathrm{C}_{2}$ reaches zero, body diode $\mathrm{D}_{2}$ freewheels the inductor current. The status equations are the same as those in stage 1.

\section{Mode $2\left(\mathrm{~V}_{\mathrm{o}}<0\right)$}

Since the analysis for this mode is complementary to the afore-presented $\mathrm{V}_{0}>0$ mode, it will be omitted here.

It is worth noting that a power MOSFET is commonly considered as a unidirectional switch since it blocks voltage only in one direction. However, a power MOSFET can conduct current in both directions. The operation of low voltage power MOSFETs in their third quadrant (when $\mathrm{V}_{\mathrm{ds}}<0$ and $\mathrm{I}_{\mathrm{ds}}<0$ ) is widely used in synchronous rectifier buck converters. The use of higher voltage (i.e. $600 \mathrm{~V}$ in our case) power MOSFET in the third quadrant is less common, but it follows a similar operation principle.

\section{B. Control Design}

Assuming that the dead time is much smaller than the turn-on time and turn-off time, according to the voltage-second balance across inductor $\mathrm{L}_{\mathrm{s}}$, an expression can be easily derived as:

$$
\left(\mathrm{V}_{\text {in }}-\mathrm{u}_{\mathrm{o}}\right) \mathrm{t}_{\mathrm{on}}=\mathrm{u}_{\mathrm{o}} \mathrm{t}_{\mathrm{off}}
$$

Where $t_{\text {on }}$ stands for the turn-on time; $t_{\text {off }}$ stands for the turn-off time; and $t_{\text {deadtime }}$ stands for the dead time, as illustrated in Fig. 4, which is ignored in equation (4).

As previously analyzed, the key point of this soft switching technique is that the inductor current should be large enough to generate the zero voltage condition during the switching transition periods. As illustrated in Fig. $4, t_{4}-t_{5}$ has a smaller inductor current than $t_{1}-t_{2}$. As a result, $t_{D}$ for this period is longer. Therefore, $t_{\text {deadtime }}$ should be selected so that it is larger than $t_{D}$, and can be expressed as:

$$
\mathrm{t}_{\text {deadtime }}>\frac{\left(\mathrm{C}_{1}+\mathrm{C}_{2}\right) \mathrm{V}_{\text {in }}}{\Delta \mathrm{I}} \geq \mathrm{t}_{\mathrm{D}}
$$

To ensure that the average output current of every switching cycle is equal to $I_{o, \text { peak }} \sin \omega t$, (as illustrated in Fig. 2) the inductor peak-to-peak current increment during every switching cycle has to satisfy the following equation:

$$
\frac{\mathrm{V}_{\text {in }}-\left|\mathrm{u}_{\mathrm{o}}\right|}{\mathrm{L}_{\mathrm{s}}} \mathrm{t}_{\text {on }}=2\left(\mathrm{I}_{\mathrm{o}, \text { peak }}|\sin \omega \mathrm{t}|+\Delta \mathrm{I}\right)
$$

By combining (4) and (6), the turn-on and turn-off time can be calculated by:

$$
\left\{\begin{array}{l}
\mathrm{t}_{\text {on }}=\frac{2 \mathrm{~L}_{\mathrm{s}}\left(\mathrm{I}_{\mathrm{o}, \text { peak }}|\sin \omega \mathrm{t}|+\Delta \mathrm{I}\right)}{\mathrm{V}_{\text {in }}-\mathrm{V}_{\mathrm{o}, \text { peak }}|\sin \omega \mathrm{t}|} \\
\mathrm{t}_{\text {off }}=\frac{2 \mathrm{~L}_{\mathrm{s}}\left(\mathrm{I}_{\mathrm{o}, \text { peak }}|\sin \omega \mathrm{t}|+\Delta \mathrm{I}\right)}{\mathrm{V}_{\mathrm{o}, \text { peak }}|\sin \omega \mathrm{t}|}
\end{array}\right.
$$

Based on (7), a digital controller can be built to calculate the turn-on and turn-off times based on the sensing of $\mathrm{V}_{\text {in }}$ and $\mathrm{V}_{\mathrm{o}}$. The control block is shown in Fig. 5.

In Fig. 5, $\mathrm{I}_{\text {ref }}$ is the desired sinusoid waveform $\mathrm{I}_{\mathrm{o} \text {,peak }}|\sin \omega \mathrm{t}|$ of the output current. $\mathrm{I}_{\text {ref }}$ can be generated by the output power 


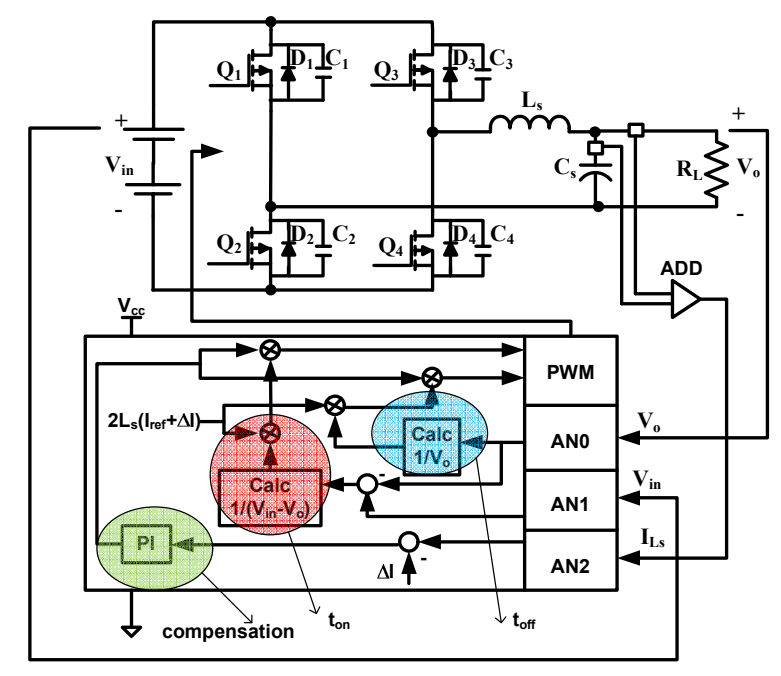

Fig. 5. Control block of BCM inverter.

and a PI regulator for $\mathrm{V}_{\mathrm{o}}$. This can make the system operate as a voltage source inverter. $I_{\text {ref }}$ can also be pre-decided and pre-saved in the DSP. In this case the inverter can operate as an AC current source. Fig. 5 illustrates $I_{\text {ref }}$ as a pre-saved parameter.

When the required output voltage is changed to $\mathrm{V}_{\mathrm{o}}<0$, the calculations of $t_{\text {on }}$ and $t_{\text {off }}$ are still the same, except that $Q_{3}$ and $\mathrm{Q}_{4}$, and $\mathrm{Q}_{1}$ and $\mathrm{Q}_{2}$ exchange their status.

To ensure that the reverse-current is at the desired value $\Delta \mathrm{I}$, as illustrated in Fig. 2, a compensation block can be provided to $t_{\text {on }}$ and $t_{\text {off. }}$. As illustrated in Fig. 5, a PI regulator generates the compensation value by comparing the sampling value $\mathrm{I}_{\mathrm{Ls}}$ with the given $\Delta \mathrm{I}$. The sampling of $\mathrm{I}_{\mathrm{Ls}}$ is triggered by the falling edge $\mathrm{V}_{\mathrm{g} 1}\left(\mathrm{~V}_{\mathrm{g} 2}\right)$, as illustrated in Fig. 4, for modes $\mathrm{V}_{\mathrm{o}}>0$ $\left(\mathrm{V}_{\mathrm{o}}<0\right)$. ADC is repeated several times until the minimum value is measured, so that the real reverse-current can be sensed. The compensation operation frequency can be lower than the switching frequency.

Since the inductor current includes both the switching frequency and the line frequency it is difficult to measure with a single transformer. As illustrated in Fig. 5, the inductor current can be sensed with a high frequency current transformer and a low frequency current sensor chip, which operate separately and are added to the capacitor and the output side inductor.

\section{DESIGN CONSIDERATIONS}

By adding the turn-on and turn-off times in (7) together, the relationship between the switching frequency and the other system parameters can be derived as:

$$
F_{s}=\frac{V_{o, \text { peak }}|\sin \omega t|\left(V_{\text {in }}-V_{o, \text { peak }}|\sin \omega t|\right)}{2 L_{s} V_{\text {in }}\left(I_{o} \text {, peak }|\sin \omega t|+\Delta I\right)}
$$

For the proper design of the BCM inverter, once the operation condition is decided, the main circuit parameters can be specified. To give a design example, suppose that the input

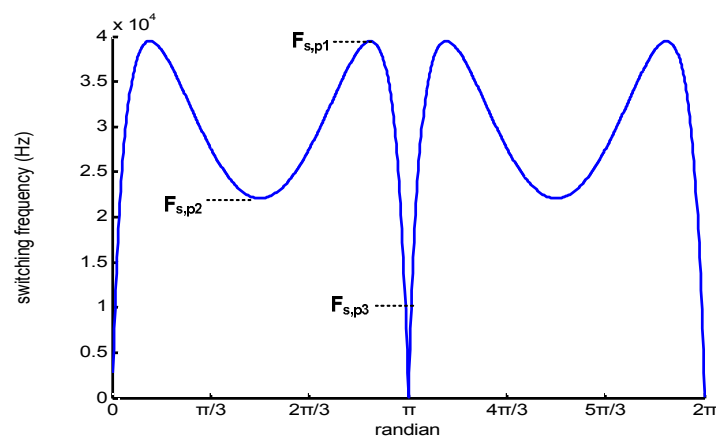

Fig. 6. Switching frequency waveform of BCM inverter.

DC voltage is $250 \mathrm{~V}$; the peak value of the output ac voltage is $170 \mathrm{~V}$ with a line frequency of $60 \mathrm{~Hz}$; and the rated power is $150 \mathrm{~W}$. Considering the voltage and current stresses of the switches in this design example, the FCP20N60 MOSFET is selected to build the inverter system.

For the switching frequency design, Fig. 6 shows the waveform of the switching frequency vs $\omega$ t calculated by (8) in a full line cycle $(\omega t \in(0,2 \pi))$. Regardless of the vertical-axis value, the waveform shape is the same for different system parameters. It can be clearly seen in Fig. 6 that the switching frequency increases/decreases rapidly near $k \pi(k$ is integer $0,1,2 \ldots$ ) and achieves zero at the points of $k \pi$. For practical considerations, usually the switching frequency is not increased from zero to the maximum value, as shown in Fig. 6. Therefore, when the switching frequency drops close to zero, all four switches can be turned off at the same time until the switching frequency rises away from zero again. This period is identified as the all-off period in this paper. When the all-off period is small enough, the output voltage distortion caused by this period can be neglected. (When the all-off period is less than $\pi / 36$, the THD caused by this period is less than $1 \%$.)

The maximum and minimum values of the switching frequency can be calculated by differentiating (8), as shown in (9) and (10). In addition, the all-off period restriction is considered to get the switching frequency range, as shown in (11).

$$
\begin{gathered}
\mathrm{F}_{\mathrm{s}, \mathrm{p} 1}=\frac{\beta\left(\mathrm{V}_{\text {in }}-\beta\right)}{2 \mathrm{~L}_{\mathrm{s}} \mathrm{V}_{\text {in }}(\alpha+\Delta \mathrm{I})} \\
\mathrm{F}_{\mathrm{s}, \mathrm{p} 2}=\frac{\mathrm{V}_{\mathrm{o}, \text { peak }}\left(\mathrm{V}_{\text {in }}-\mathrm{V}_{\mathrm{o}} \text { peak }\right)}{2 \mathrm{~L}_{\mathrm{s}} \mathrm{V}_{\text {in }}\left(\mathrm{I}_{\mathrm{o} \text {, peak }}+\Delta \mathrm{I}\right)}
\end{gathered}
$$

Where:

$$
\begin{gathered}
\alpha=\frac{-V_{o, \text { peak }} \Delta \mathrm{I}+\sqrt{\mathrm{V}_{\mathrm{o}, \text { peak }} \Delta \mathrm{I}\left(\mathrm{V}_{\mathrm{o}, \text { peak }} \Delta \mathrm{I}+3 \mathrm{I}_{\mathrm{o}, \text { peak }} \mathrm{V}_{\text {in }}\right)}}{3 \mathrm{~V}_{\mathrm{o} \text {, peak }}} \\
\beta=\frac{-\mathrm{V}_{\mathrm{o} \text {, peak }} \Delta \mathrm{I}+\sqrt{\mathrm{V}_{\mathrm{o}, \text { peak }} \Delta \mathrm{I}\left(\mathrm{V}_{\mathrm{o}, \text { peak }} \Delta \mathrm{I}+3 \mathrm{I}_{\mathrm{o}, \text { peak }} \mathrm{V}_{\text {in }}\right)}}{3 \mathrm{I}_{\mathrm{o} \text {, peak }}} \\
\mathrm{F}_{\mathrm{s}, \mathrm{p} 3}=\left.\mathrm{F}_{\mathrm{s}}\right|_{\omega \mathrm{t}}=\frac{\pi}{72}
\end{gathered}
$$

Fig. 7 shows the boundary switching frequencies varying with the reverse current $\Delta \mathrm{I}$. (as the inductance of Ls has not 


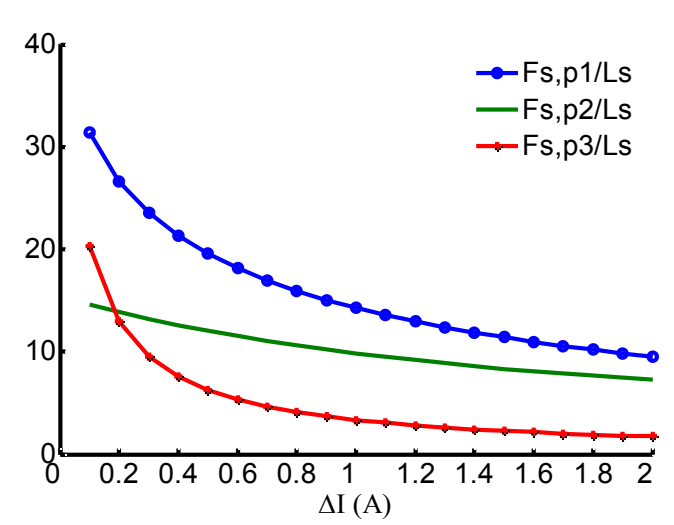

Fig. 7. Switching frequency range waveform.

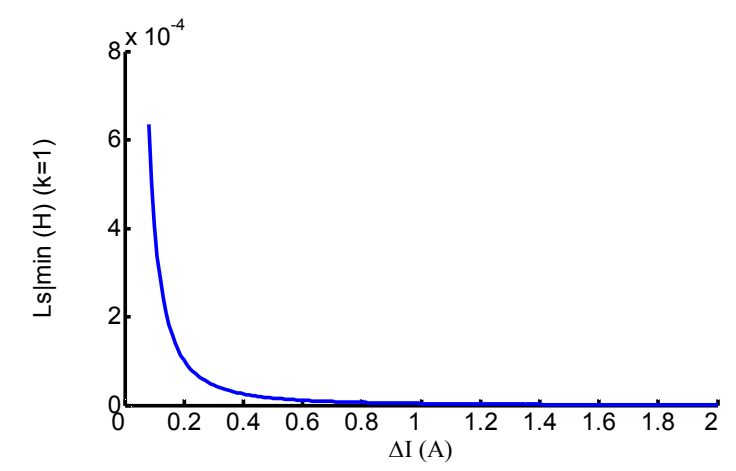

Fig. 8. Minimum $\mathrm{L}_{\mathrm{s}}$ waveform with $\mathrm{k}=1$.

been specified, the vertical-axis switching frequency is divided by Ls in Fig. 7) When I is larger than $0.2 \mathrm{~A}$, the boundary frequencies are decided by Fs,p1 and Fs,p3. Moreover, with an increase of $I$, the boundary switching frequencies and the frequency range decrease together.

According to (6), the minimum value of $t_{\text {on }}$ (achieves at $\mathrm{V}_{\mathrm{o}}=0$ ) could be derived to get the restriction of $\mathrm{L}_{\mathrm{s}}$,

$$
\mathrm{t}_{\text {on, } \min }=\frac{2 \mathrm{~L}_{\mathrm{s}} \Delta \mathrm{I}}{\mathrm{V}_{\text {in }}}
$$

The calculations of $t_{\text {on }}$ and $t_{\text {off }}$ are based on (4), which neglects the dead time. To guarantee the accuracy of the calculations, the minimum value of $t_{\text {on }}$ should be much larger than the dead time. Thus, (5) and (12) are combined to get a restriction for the $\mathrm{L}_{\mathrm{s}}$ design.

$$
\mathrm{L}_{\mathrm{s}} \geq \frac{\mathrm{k}\left(\mathrm{C}_{1}+\mathrm{C}_{2}\right) \mathrm{V}_{\text {in }}^{2}}{2 \Delta \mathrm{I}^{2}}
$$

The larger the value of $\mathrm{k}$, the less distortion is caused by neglecting the dead time, thus the more accurate the calculations of $\mathrm{t}_{\text {on }}$ and $\mathrm{t}_{\text {off }}$ become.

Fig. 8 is drawn from (13) to show the minimum value of inductor $\mathrm{L}_{\mathrm{s}}$ when $\mathrm{k}=1$. The output capacitance can be obtained from the datasheet of a FCP20N60.

Fig. 8 illustrates that with an increase of $\Delta \mathrm{I}$, the minimum

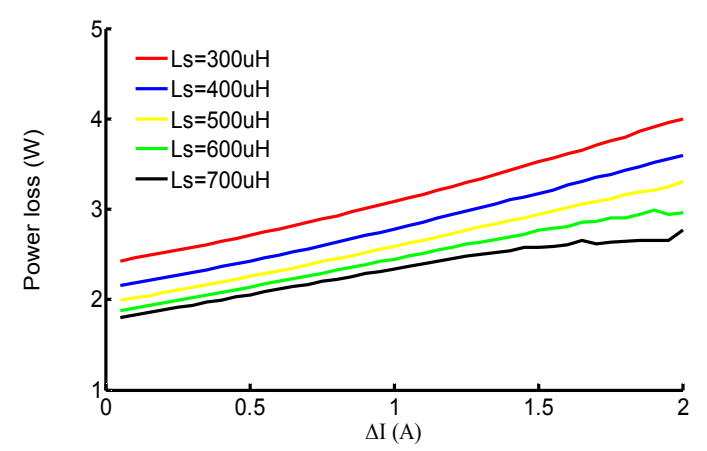

(a)

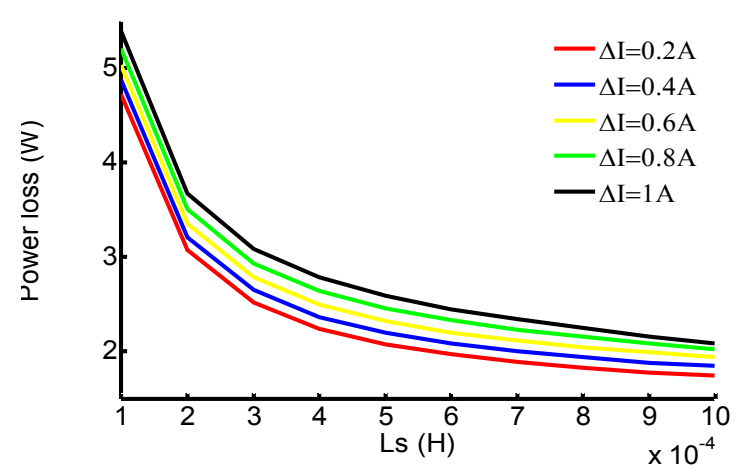

(b)

Fig. 9. Power loss waveforms.

requirement of $\mathrm{L}_{\mathrm{s}}$ decreases.

Thus, based on Fig. 7 and Fig. 8, it is preferable for $\Delta \mathrm{I}$ be larger to have a smaller inductance and a narrower switching frequency range. This results in a smaller size and a higher power density.

Although the proposed BCM control method realizes zero voltage switching during the turn-on period, there are still various losses for the inverter system such as the inductor and MOSFETs conduction losses, antiparallel diode loss, MOSFETs turn-off switching losses, inductor core losses, etc. To optimize the parameter section for the inverter system efficiency consideration, the power losses are calculated with Mathcad. (As inductor core losses is very difficult to calculate under various frequencies with various duty cycles. Thus, it is not included here.) The power loss waveforms are illustrated in Fig. 9.

Fig. 9.(a) shows the power loss vs. the $\Delta \mathrm{I}$ waveforms under various $L_{s}$, while Fig. 9.(b) shows the power loss vs. the $L_{s}$ waveforms under various $\Delta \mathrm{I}$.

Fig. 9.(a) illustrates that the power loss increases approximate linearly with a decreasing of $\Delta \mathrm{I}$; while Fig. 9 (b) illustrates that the power loss increases more and more rapidly with a decreasing of $L_{s}$. Thus, from Fig. 9, it can be seen that $L_{s}$ has to be larger than $400 \mathrm{uH}$ and $\Delta \mathrm{I}$ should be as small as possible.

To balance the efficiency requirements with the size and 


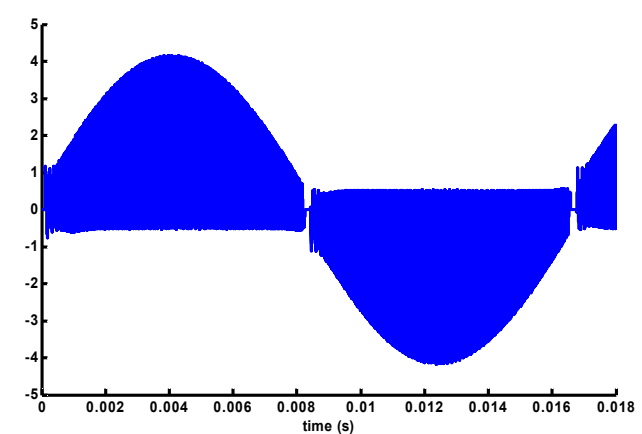

(a)

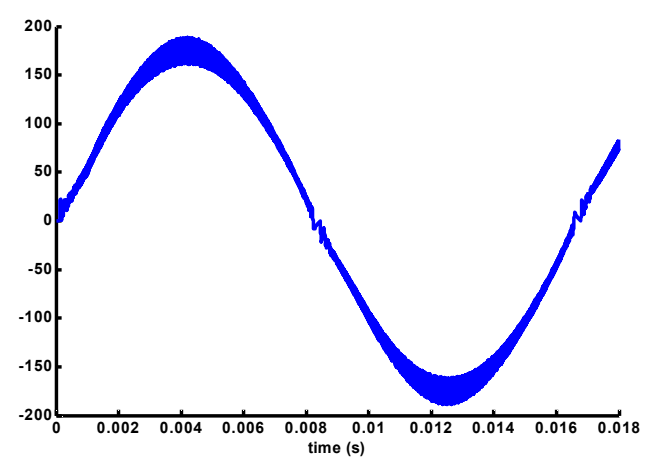

(b)

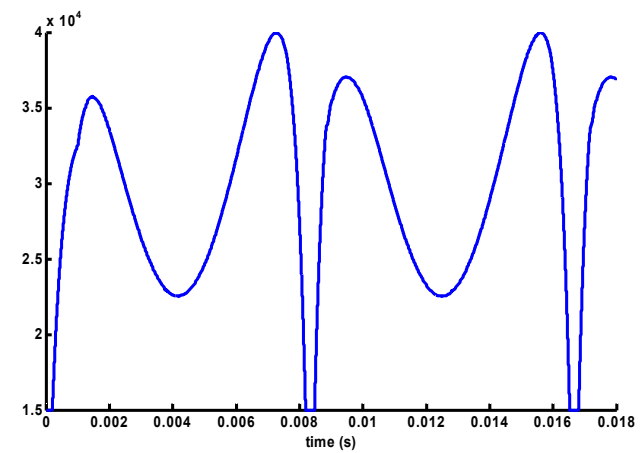

(c)

Fig.. 10. BCM inverter simulation waveforms: (a) inductor current waveform, (b) output voltage waveform, (c) switching frequency waveform.

switching frequency range requirements, a trade-off decision has to be carefully made.

For the nonlinear relationship of the boundary frequencies vs. $\Delta \mathrm{I}$, as illustrated in Fig. 7, $\Delta \mathrm{I}$ should be larger than $0.3 \mathrm{~A}$ to have smaller boundary frequencies. From Fig. 8, assume that $\mathrm{k}=10$ (The minimum $\mathrm{L}_{\mathrm{s}}$ can be calculated by multiplying the vertical-axis value of Fig. 8 with 10.) is large enough to ignore the dead-time-distortion. For $\Delta \mathrm{I}=0.2 \mathrm{~A} \mathrm{~L}_{\mathrm{s}} \mid \mathrm{min}$ is about $1000 \mathrm{uH}$, and for $\Delta \mathrm{I}=0.4 \mathrm{~A} \mathrm{~L}_{\mathrm{s}} \mid \mathrm{min}$ is about $270 \mathrm{uH}$.

Considering all of the above restrictions, the parameters are selected to be $\Delta \mathrm{I}=0.4 \mathrm{~A}$ and $\mathrm{L}_{\mathrm{s}}=500 \mathrm{uH}$, and the relevant boundary switching frequencies are $15 \mathrm{kHz}$ and $42.6 \mathrm{kHz}$. The overall calculated efficiency is $98.7 \%$.

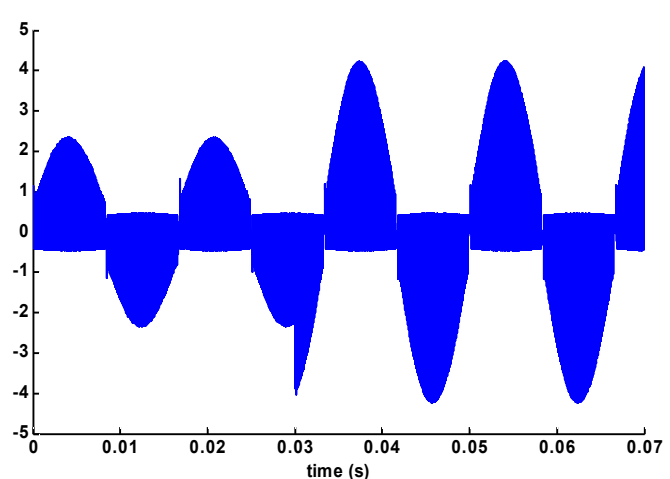

(a)

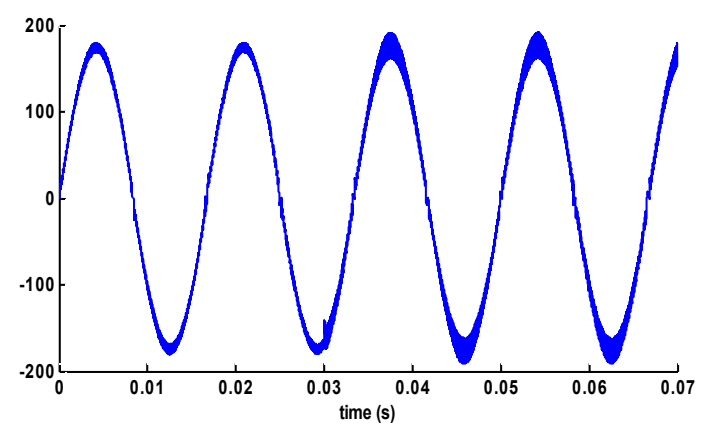

(b)

Fig. 11. BCM inverter simulation waveforms with sudden changing at $\mathrm{t}=0.03 \mathrm{~s}$ from half load to full load: (a) inductor current waveform, (b) output voltage waveform

\section{Simulation RESUlts}

MATLAB Simulink was used to simulate the proposed control algorithm. The parameters of the single-phase inverter simulation system are set as: Input: $250 \mathrm{~V}_{\mathrm{dc}}$; output: $170 \mathrm{~V}_{\mathrm{ac}, \mathrm{pk}}$; rated power: $150 \mathrm{~W}, 60 \mathrm{~Hz}$; switching frequency: $15 \mathrm{kHz} \sim 40 \mathrm{kHz} ; \mathrm{L}_{\mathrm{s}}=540 \mathrm{uH} ; \mathrm{C}_{\mathrm{s}}=1 \mathrm{uF}$; and $\Delta \mathrm{I}=0.5 \mathrm{~A}$.

Fig. 10.(a) shows the inductor current waveform, which indicates that the inverter operates under the BCM mode as expected. Fig. 10.(b) shows the waveform of the output voltage; and Fig. 10.(c) shows the switching frequency waveform.

The waveform in Fig. 10.(c) is similar to the waveform in Fig.6. The only difference is caused by the compensation of $\Delta \mathrm{I}$ mentioned in the control design section.

The simulation results verify that the proposed control algorithm operates as theoretically analyzed in section II.

To illustrate the transient operation of the proposed digital controller (when the BCM inverter operates as a voltage source), a simulation is carried out with the output power changing suddenly from half load to full load. The inductor current and output voltage waveforms are shown as in Fig. 11.

As illustrated in Fig. 11, the load change happens at $\mathrm{t}=0.03 \mathrm{~s}$. The inductor current (as shown in Fig. 11(a)) and 


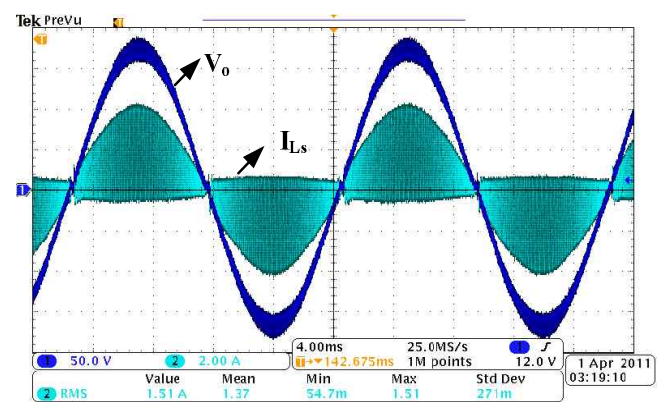

(a)

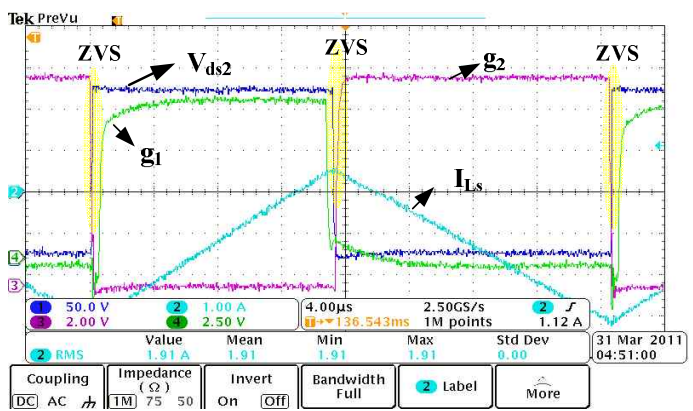

(b)

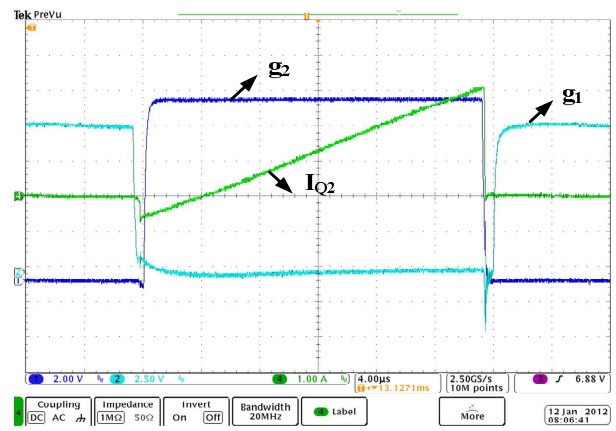

(c)

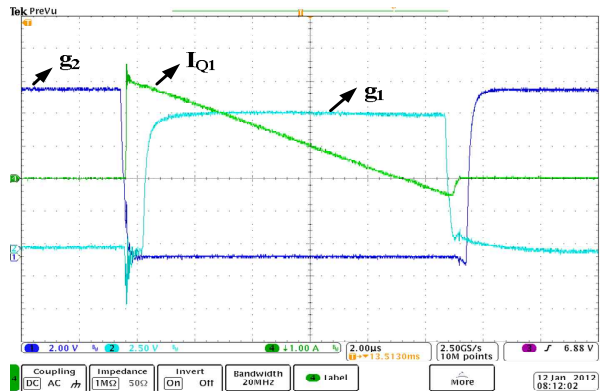

(d)

Fig. 12. BCM inverter waveforms: (a)output voltage \& inductor current (b) zero voltage switching waveforms (c) current through MOSFET $\mathrm{Q}_{2}$ and driver signals for MOSFETs $\mathrm{Q}_{1} \& \mathrm{Q}_{2}$ (d) current through MOSFET $\mathrm{Q}_{1}$ and driver signals for MOSFETs $\mathrm{Q}_{1} \& \mathrm{Q}_{2}$

output voltage maintain the desired waveform (as shown in Fig. 11(b)).

\section{EXPERIMENTAL RESULTS}

A $150 \mathrm{~W}$ full-bridge inverter prototype was built to implement the proposed control scheme. The digital

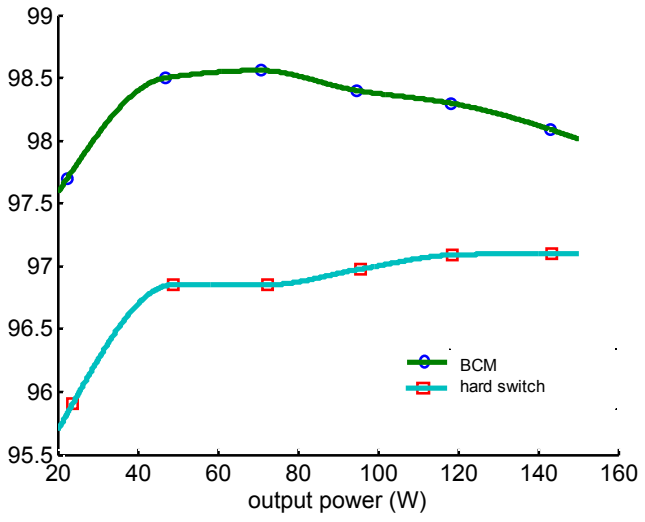

Fig. 13. Efficiency waveform of BCM inverter.

controller is implemented by a dspic30f2023 microchip. The parameters of the circuit system are set as below:

Input: $250 \mathrm{~V}_{\mathrm{dc}}$; output: $170 \mathrm{~V}_{\mathrm{ac}, \mathrm{pk}}$; rated power: $150 \mathrm{~W}, 60 \mathrm{~Hz}$; switching frequency: $15 \mathrm{kHz} \sim 41 \mathrm{kHz} ; \mathrm{L}_{\mathrm{s}}=561 \mathrm{uH} ; \mathrm{R}_{\mathrm{s}}=0.2 \Omega$; $\mathrm{C}_{\mathrm{s}}=1 \mathrm{uF} ;$ and $\Delta \mathrm{I}=0.4 \mathrm{~A}$.

Fig. 12(a) shows the output voltage and inductor current. Both are similar to the simulation results in section IV. Fig. 12(b) shows the two complementary driving signals of the high frequency leg, the drain source voltage across one of the MOSFETs, and the current through the inductor. It can be clearly seen from Fig. 12(b) that before the arrival of $g_{2}, V_{d s 2}$ across MOSFET $\mathrm{Q}_{2}$ has already decreased to zero. Before the arrival of $g_{1}, V_{d s 2}$ has already increased to its maximum. Thus, the ZVS is successfully realized during the switches transitions. Fig. 12(c) and (d) show key the waveforms for $\mathrm{Q}_{1}$ and $\mathrm{Q}_{2}$ individually. They operate exactly the same as in Fig. 4. They also confirm that although power MOSFETs operating in the third quadrant is not common, they are practicable.

To give a comparison of the proposed soft switching technique, continuous conduction mode (CCM) hard switching control is implemented on the same prototype. The detailed parameters are as follows:

Input voltage: 250 $\mathrm{V}_{\mathrm{dc}}$; output: 170 $\mathrm{V}_{\mathrm{ac}, \mathrm{pk}} @ 150 \mathrm{~W}, 60 \mathrm{~Hz}$; switching frequency: $20 \mathrm{kHz} ; \mathrm{L}_{\mathrm{s}}=2.61 \mathrm{mH} ; \mathrm{R}_{\mathrm{s}}=0.6 \Omega$; and $\mathrm{C}_{\mathrm{s}}=1 \mathrm{uF}$.

Fig. 13 shows an efficiency comparison between the BCM and the hard-switching techniques. The peak efficiency of the $\mathrm{BCM}$ technique can reach up to $98.5 \%$, which is $1.5 \%$ higher than the peak efficiency of the hard switching technique. All of the efficiency measurements were implemented by a PZ4000 power analyzer. The measured efficiency does not include the driving power loss.

\section{CONCLUSIONS}

This paper proposes a novel soft switching technique for conventional full-bridge single phase DC/AC inverters. The 
ZVS can be realized on all of the switches by operating the inductor current under the BCM control scheme. When compared with the hard switching inverter, it improves the efficiency without introducing additional components.

The operation principle of the proposed ZVS technology was analyzed in detail by dividing the operation progress into six stages. The equivalent circuits and key waveforms of each stage were discussed carefully to reveal the soft-switching characteristics. The digital control strategy was analyzed carefully to implement the proposed BCM technique. An example was given to introduce the design considerations and to aid in the inverter system parameter selections. A $150 \mathrm{~W}$ inverter prototype was built under the design guideline to carry out the experiments. The experimental results verify the operation principle and the control analysis.

\section{REFERENCES}

[1] X. Yuan and Y. Zhang, "Status and opportunities of photovoltaic inverters in grid-tied and micro-grid systems," in Proc. IPEMC, pp.1-4, Aug. 2006.

[2] H. Sugimura, H. Muraoka, T. Ahmed, S. Chandhaket, E. Hiraki, M. Nakaoka, and H. Lee, "Dual mode phase-shifted ZVS-PWM series load resonant high-frequency inverter for induction heating super heated steamer," Journal of Power Electronics, Vol. 4, No. 3, pp.138-151, Jul. 2004.

[3] K. Fathy, S. Kwon, and M. Nakaoka, "Advanced induction heating equipment using dual mode PWM-PDM controlled series load resonant tank high frequency inverters," Journal of Power Electronics, Vol. 7, No. 3, pp.246-256, Jul. 2007.

[4] C. Wang, "Nonlinear-controlled strategy for soft-switched series-resonant DC/AC inverter without auxiliary switches," IEEE Trans. Power Electron., Vol. 18, No. 3 , pp. 764-774, May. 2003.

[5] A. Muthuramalingam, S. V. Vedula, and P. A. Janakiraman, "Performance evaluation of an FPGA controlled soft switched inverter," IEEE Trans. Power Electron., Vol. 21, No. 4 , pp. 923-932, Jul. 2006.

[6] K. Ogura, S. Chandhaket, M. Nakaoka, H. Terai, S. Sumiyoshi, T. Kitaizumi, and H. Omori, "Utility- connected solar power conditioner using edge-resonant soft switching duty cycle sinewave modulated inverter link," Journal of Power Electronics, Vol. 2, No. 3, pp. 181-188, Jul. 2002.

[7] M. Mahdavi, M. R. Amini, A. Emrani, and H. Farzanehfard, "Soft switching three phase inverter with two auxiliary switches, " Journal of Power Electronics, Vol. 11, No. 6, pp.787-792, Nov. 2011.

[8] T. Ahmed, S. Nagai, M. Nakaoka, and T. Tanaka, "Utility-interactive four-switch three-phase soft-switching inverter with single resonant DC-link snubber and boost chopper," Journal of Power Electronics, Vol. 7, No. 2, pp.109-117, Apr. 2007.

[9] H. Iyomori, S. Nagai, M. Yoshida, E. Hiraki, and M. Nakaoka, "Power module bridge type auxiliary resonant AC link Snubber-assisted three-phase soft switching inverter," Journal of Power Electronics, Vol. 4, No. 2, pp.77-86, Apr. 2004.

[10] E. Hiraki and M. Nakaoka, "Performance evaluations of digitally-controlled auxiliary resonant commutation snubber-assisted three phase voltage source soft switching inverter," Journal of Power Electronics, Vol. 3, No. 1, pp.1-9, Jan. 2003.

[11] W. Yu, J. Lai, and S. Park, "An improved zero-voltage switching inverter using two coupled magnetics in one resonant pole," IEEE Trans. Power Electron., Vol. 25, No. 4 , pp. 952-961, Apr. 2011.

[12] H. Zhang, Q. Wang, E. Chu, X. Liu, and L. Hou, "Analysis and implementation of a passive lossless soft-switching snubber for pwm inverters," IEEE Trans. Power Electron., Vol. 26, No. 2, pp. 411-426, Feb. 2011.

[13] Y. P. Li, F. C. Lee, and D. Boroyevich, "A simplified three-phase zero-current-transition inverter with three auxiliary switches," IEEE Trans. Power Electron., Vol. 18, No. 3, pp. 802-813, May 2003.

[14] C. Y. Inaba, E. Hiraki, and M. Nakaoka, "Three phase voltage source soft switching inverter with high frequency pulse current transformers," Journal of Power Electronics, Vol. 2, No. 4, pp.288-296, Oct. 2002.

[15] M. Chen, Z. Zhang, M. Gao, and Z. Qian, "Research on a non-complementary active clamp flyback converter with unfolding DC-AC inverter for decentralized grid-connected PV systems," in Proc. ECCE, pp.2481-2487, Sep. 2011.

[16] J. Gu, H. Wu, G. Chen, and Y. Xing, "Research on photovoltaic grid-connected inverter based on soft-switching interleaved flyback converter," in Proc. ICIEA, pp.1209-1214, Jun. 2010.

[17] C. Zhao, X. Wu, Z. Qian, "Optimum design considerations for soft-switched phase-shift full-bridge converter with primary-side energy storage inductor," in Proc. PESC, pp 366-371, Jun. 2008.

[18] X. Wu, J. Yang, J. Zhang, and M. Xu, "Design consideration of soft-switched Buck PFC converter with constant on-time (COT) control," IEEE Trans. Power electron., Vol. 26, No. 11, pp. 802-813, Nov. 2011.

[19] C. Chakraborty, S. Dalapati, and S. Bhattacharya, "Performance evaluation of controlled-capacitor-chargingtype inverters," IEEE Trans. Ind. Electron., Vol. 56, No. 1, pp. 12-19, Jan. 2009.

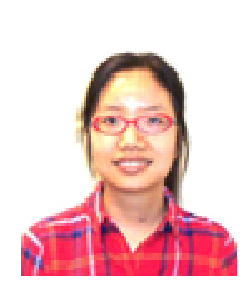

Qian Zhang received her B.S. from the Huazhong University of Science and Technology, Wuhan, China, in 2006, and her M.S. in Electrical Engineering from Wuhan University, Wuhan, China, in 2008. She is currently pursuing her Ph.D. at the University of Central Florida, Orlando, FL, USA. Her current research interests include digital control in power electronics, single-phase and three-phase power factor corrections and single-phase and three-phase DC/AC inverters.

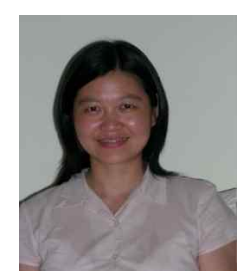

Dehua Zhang received her B.S., M.S. and Ph.D. in Electrical Engineering from Zhejiang University, Hangzhou, China, in 1993, 1996 and 2002, respectively. She was an Associate Professor in the College of Electrical Engineering, Zhejiang University. In 2011, she joined the Department of Electrical Engineering, University of Central Florida, Orlando, FL, USA, as a Research Scholar. Her current research interests include digital control in power electronics and soft switching inverters. Dr. Zhang has authored and coauthored more than 20 technical papers published in journals and conference proceedings. 


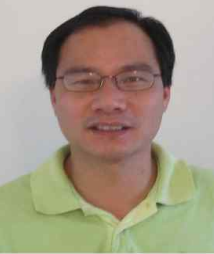

Haibing Hu received his B.S. from the Hunan University of Technology, Changsha, China, in 1995, and his M.S. and Ph.D. in Electrical Engineering from Zhejiang University, Hangzhou, China, in 2003 and 2007, respectively. From 2007 to 2009, he was an Assistant Professor in the Department of Control Engineering, Nanjing University of Aeronautics and Astronautics, Nanjing, China, where he is currently an Associate Professor. In 2009, he joined the Department of Electrical Engineering, University of Central Florida, Orlando, FL, USA, as a Post-Doctoral Research Fellow. His current research interests include digital control in power electronics, multilevel inverters, digital control system integration for power electronics, applying power electronics to distributed energy systems and power quality. Dr. $\mathrm{Hu}$ has authored and coauthored more than 50 technical papers published in journals and conference proceedings.

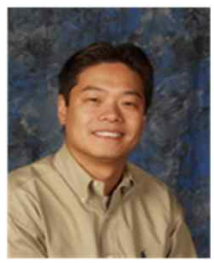

John Shen received his B.S. in Electrical Engineering from Tsinghua University, Beijing, China, in 1987, and his M.S. and Ph.D. in Electrical Engineering from the Rensselaer Polytechnic Institute, Troy, NY, USA, in 1991 and 1994, respectively. Between 1994 and 1999, he held a number of technical positions, including Senior Principal Staff Scientist with Motorola Semiconductor Products Sector, Phoenix, AZ. Between 1999 and 2004, he was with the University of Michigan-Dearborn, Dearborn, MI, USA. Since 2004, he has been with the University of Central Florida, Orlando, FL, USA, where he is currently a Professor of Electrical Engineering, the Director of the Power Semiconductor Research Laboratory, and the Associate Director of the Florida Power Electronics Center. His current research interests include power semiconductor devices and integrated circuits, power electronics, automotive electronics, nanotechnology, and renewable-energy systems. He has authored or coauthored over 100 technical papers published in journals and conference proceedings. He is the holder of 12 issued and several pending or provisional U.S. patents. He is the inventor of the world's first submilliohm power metal-oxide-semiconductor field-effect transistor. Dr. Shen served as an Associate Editor of the IEEE Transactions on Power Electronics, between 2006 and 2009. He served as the Technical Program Chair of the second IEEE Energy Conversion Congress and Expo, in 2010; the 38th IEEE Power Electronics Specialists Conference, in 2007; and the first IEEE Vehicle Power and Propulsion Conference, in 2005. He is currently serving as the Vice President of Products of the IEEE Power Electronics Society. He has also served on numerous IEEE conference and workshop organizing committees, and international editorial boards. He was a recipient of the 2003 U.S National Science Foundation Career Award; the 2006 Transaction Prize Paper Award of the IEEE Transactions on Power Electronics, from the IEEE Power Electronics Society; the 2003 IEEE Best Automotive Electronics Paper Award from the IEEE Transactions on Vehicular Technology; and the 1996 Motorola Science and Technology Award.

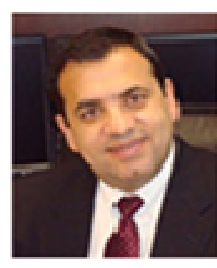

Issa Batarseh received his B.S. in Electrical and Computer Engineering, and his M.S. and $\mathrm{Ph} . \mathrm{D}$. in Electrical Engineering from the University of Illinois, Chicago, IL, USA, in 1983, 1985, and 1990, respectively. He is currently a Professor of Electrical Engineering with the School of Electrical Engineering and Computer Science, University of Central Florida (UCF), Orlando, FL, USA. From 1989 to 1990, he was a Visiting Assistant Professor with Purdue University Calumet, Hammond, IN, USA, before joining the Department of Electrical and Computer Engineering, UCF, in 1991. His current research interests include power electronics, developing high-frequency energy conversion systems to improve power density, efficiency, and performance, the analysis and design of high-frequency solar and wind energy conversion topologies, and power factor correction techniques. He is the author or coauthor of more than 300 conference papers and 60 technical papers published in referenced journals. In addition, he is the holder of 14 U.S. patents. He is also the author of a textbook entitled "Power Electronic Circuits" (New York: John Wiley, 2003). Dr. Batarseh is a Registered Professional Engineer in the State of Florida and a Fellow Member of the IEEE. He has served as a Chairman for the IEEE PESC'07 conference and was the Chair of the IEEE Power Engineering Chapter, and the IEEE Orlando Section. 